\title{
Jacob Bull
}

\section{Salmon tales}

Peter Coates. Salmon. London: Reaktion Books Ltd, 2006. 216 pp. $£ 12.95 \$ 19.95$ (pb)

Fishes so often escape our (human) concern. Practically, they are rarely encountered except possibly in aquaria, on the plate or the fishmonger's bed of crushed ice. Moreover, fishes occupy spaces which are so fundamentally alien to human ways of knowing that the use of the large-scale, industrial trawlers that are so ethically and environmentally contentious can almost be understood. Indeed, their continued existence is evidence of our failure to place fishes within the schema of intellectual and social moral concern (see Jones 2000). It is therefore superb to find such a work on salmon in the Animal series, and the concern Coates shows for the subject is careful and stimulating. The range of topics included in the text is wide reaching, covering the biological understandings of salmon, cultural significance, tins of salmon, a salmonskin-bikini, and the conflicts which arise between different social groups and individuals as well as between humans and salmon.

The first substantive chapter is concerned with the biological salmon. It offers a brief introduction to all of the eight species of salmon that exist in the Atlantic and Pacific oceans. It also offers an introduction to the lifecycle of these salmon, describing the various stages of its freshwater life from egg, through alevin to fry, par and then smolt. It is in this smolt stage that the salmon begins its physiological change to adapt to saline conditions in preparation for its time feeding at sea. Through this chapter the reader is given a wonderful insight into the scientific, historical and "lay" knowledges that led to the current understandings of the salmon as a biological entity and subject for scientific enquiry. The experiments conducted to ascertain how a fish may travel thousands of miles at sea only to return to the river of its birth highlight the different corporeal ontologies of aquatic habitats. This great journey, the almost unbelievable ability to end where one began, is emphasized through the chapter, and clearly identifies why salmon can be considered as charismatic species despite their alien habitat. ${ }^{1}$

The beginning of the second chapter further underlines the heroic narrative of the returning salmon as it is faced by various human and non-human predators. What follows in the rest of the chapter is an interesting account of the social and cultural value of salmon as a food through history and across the globe. The main focus of the 
chapter is a history of the tinned salmon industry which grew up on the East coast of the United States, and the historical significance of tinned salmon in British culture. Contrasting with this "edible salmon" are accounts of human consumption of other parts of the animal, mainly in the form of "salmon leather" clothing. From this use of salmon Coates moves in the third chapter to the "misuse" of salmon and their habitats. This chapter focuses on the wild salmon and laments the pressures exerted on salmon populations by human activities. These concerns are not merely recent events. Coates offers a neat summary of the historical precedents to contemporary environmental issues affecting salmon populations. The latter stages of the chapter discuss the implications of fish farming, both as an option for maintaining fish stocks and the production of commodified salmon. The story of the commodified salmon echoes the plight of the broiler chicken. However, despite some concern for the implications on the bodily wellbeing of farmed salmon, the argument tends to center on the implications of farmed fish on wild stocks and human health. These controversies set up an interesting discussion in chapter four, which focuses on issues around who owns the salmon's body. It highlights the manner in which tensions between different social groups have been played out through access to salmon fishing. In addition it discusses different issues in salmon fishing from commercial, compared to subsistence, compared to recreational. It is this recreational interest that is the topic for chapter five.

In this fifth chapter Coates's traces the various written historical accounts of angling, that is recreational fishing (for salmon). He refers to many medieval and Victorian texts. These texts have become integral to the angling experience. As the chapter progresses, Coates focuses on fly-fishing over other forms of fishing, and describes how this "ostensible foolishness" (132) was exported across the globe, carrying with it the quarry anglers value so highly as "eggs on charcoal and living moss in perforated wooden boxes under ice" (133). The sixth chapter extends the significance of salmon beyond the culture of angling to discuss how salmon have gained significance, indeed mythical status in various cultures, from the heraldic motto of a Scottish-Borders town to the ceremonies of the Kwakiutl people of Vancouver Island. It is here in the analysis of the wider cultural significance of salmon that I think that Salmon begins to provoke some fundamental questions about what it is to be fish, and what it is to be human, a meeting of watery and airy inhabitants.

Overall, the book offers a wonderful introduction to some of the meetings between salmon and people. My concern perhaps with this text is that amid the clamor of science, the clash of tins, the arguments of ownership and even in the quiet moments of 
recreational angling, the stories of the animals which are salmon are not as prominent as one might hope. I wanted more of the accounts that go beyond the use-value of salmon. This book is, nonetheless, a wonderful discussion of the social cultural and historical importance of salmon. Coates does a fantastic job of elevating salmon to the position of charismatic-mega-fauna. He has in many ways achieved his intention to write "a veritable compleat ${ }^{2}$ Salmon" (p.12). I would suggest, however, that it is not quite a complete Salmon; I would like to hear the stories of the salmon that lie outside of, or at least closer to the edge of, our human understandings of fishes. This is possibly an unfair criticism, as part of the charisma of salmon species is their anadromous life cycle; that they appear in our rivers and lakes, momentarily becoming a significant feature, only to disappear to live lives elsewhere. However, I maintain that it would be interesting to hear more about the fish. Coates does begin to discuss these stories in chapter 3, the unfortunate salmon, as he identifies the ecological crises of riparian environments and development of aquaculture. But Humans stand as much more than just another predator waiting to snatch the salmon as it struggles to overcome the obstacles in its quest to do "this natural duty." 3 It would be good to consider what these fishes might be able to tell us about being fish and being human; what they may be able to communicate other than ecological disaster. I feel it is only in the passionate, insightful, at times slightly polemical, conclusion that Coates begins to deal with these questions but maybe these stories are for another book.

Despite my desire to hear more of these alternative perspectives, Salmon remains an interesting, accessible, thought provoking, and enjoyable read. It does much to counteract the social and intellectual blindness to considering fish as animals, and I thoroughly recommend it given the fact that fish so often escape our (human) concern.

\section{Notes}

1. See Lorimer $2006 / 07$ for a greater discussion of the charisma of animals as scientific subjects.

2. This spelling is a reference to Isaak Walton's compendium on angling The Compleat Angler, considered by many to be the defining text on angling.

3. Isaak Walton (2003:78) as referred to by Coates (2006: 7).

Humanimalia: a journal of human/animal interface studies

Volume 1, Number 2 (Winter 2010) 


\section{Works Cited}

Coates, Peter. Salmon. London: Reaktion, 2006.

Jones, Owain. “(Un)Ethical geographies of human-non-human relations: Encounters, collectives and spaces." Animal Beastly Places. Ed. Chris Philo and Chris Wilbert. Oxford: Routledge, 2000. 268-91.

Lorimer, Jamie. "Nonhuman charisma: which species trigger our emotions and why?" ECOS 27:1 (2006). 20-27.

Lorimer Jamie. "Nonhuman charisma." Environment and Planning D: Society and Space, 24:5 (2007). 911-32.

Walton, Isaak. The compleat angler Mineola: Dover, 2003. 